\title{
The Potential of Teacher-Led Research: Teachers' Action Research Collaborations in Science Education in Singapore
}

\author{
Gavin W. Fulmer ${ }^{1 *}$, Hye-Eun Chu ${ }^{2}$ and Sonya N. Martin ${ }^{3}$
}

\author{
* Correspondence: gavin-fulmer@ \\ uiowa.edu \\ ${ }^{1}$ College of Education, University of \\ lowa, lowa City, IA, USA \\ Full list of author information is \\ available at the end of the article
}

This special issue presents action research projects that serve as examples of research collaborations among teachers and university faculty that are practically significant to both schools and teachers while also having potential to inform theory and build scholarly knowledge. We see these examples of teacher-led research as highlights of work carried out by science teachers as education researchers in Singapore. Action research has been emphasized in Singapore for over 15 years as a way to promote school-based educational innovations and teachers' self-development (Hairon, 2006, 2017; Tang, 2000). However, to date, teacher-led and school-based research following other research models in East Asian contexts, such as Japanese lesson study and Chinese model lessons, have been more widely recognized. This dearth of published work belies the wide use of varied teacher-led research in Singaporean schools as many studies have been conducted over extended periods of time that encompass a wide range of topics. Unfortunately, relatively little has been published to describe the findings emerging from these action research projects.

The action research papers in this special issue originated from collaboration between school science teachers and university researchers and supervisors. The partnerships were bidirectional, establishing theoretical bases in teachers' action research goals while helping the researchers have more direct views of research on implementation and teacher experience in real classrooms and school settings. Despite disagreement in the literature about how action research should be implemented (Beaulieu, 2013), we see that action research is not only a tool for professional development and lesson improvement, but also could serve as an avenue for engaging teachers in scholarship. Thus, the important idea coming from this set of special issue papers is that action research not only has immense potential help to increase teachers' sense of reflection about teaching, it can also help teachers to look beyond the immediate classroom to speak to issues involving standards interpretation and implementation, novice teacher induction and retention, and more. Previously, these avenues of research were typically seen as the purview of university researchers or district personnel. Nevertheless, these studies show that teachers themselves have the capacity to develop as reflective practitioners, leaders, and researchers.

In the following introduction to this special issue, we give a brief background of the Singaporean education context and the role of action research in this context,

(c) The Author(s). 2018 Open Access This article is distributed under the terms of the Creative Commons Attribution 4.0 International License (http://creativecommons.org/licenses/by/4.0/), which permits unrestricted use, distribution, and reproduction in any medium, provided you give appropriate credit to the original author(s) and the source, provide a link to the Creative Commons license, and indicate if changes were made. 
summarize the papers that comprise the special issue, and then review the central theme from these action research reports.

\section{Background on Singapore and its education system}

Singapore's education context is an example of a markedly cosmopolitan intersection of historical structures, cultural influences, and contemporary trends. The system has notable similarities to the UK, owing to its history as a British colony and ongoing membership in the Commonwealth of Nations (Gregory \& Clarke, 2003). Singaporean students attend primary school for Grades 1-6 and secondary school for Grades 7-10, after which they have different routes depending on their own preferences, prior academic performance, and examination results. Singapore has its own adaptation of the Cambridge General Certificate of Education (GCE): The O-Level (Ordinary Level) that students sit at the end of Grade 10. Depending on their O-level results, Singaporean students may go to junior college for Grades 11-12, which prepares students for the GCE A-Level (Advanced Level) examinations and admission to university; to a polytechnic institute, which yields a three-year diploma suitable for entry-level employment in a variety of applied fields such as IT or nursing; or to a vocational education center, which offers two-year certificates in a skilled trade.

Singapore's educational context demonstrates cultural influences similar to its Asian neighbors, especially those with Confucian bases. It is an assessment-driven society, influenced by cultural values regarding standardized examination systems similar to other Asian societies (Kennedy, 2007). Singapore also has a stated goal for the education system of supporting the national interest and developing a stable nation-state. That means participating in and endorsing the Singaporean meritocratic social model, inculcating values of multiculturalism and nation building, and developing students' character, citizenship, and leadership (Gopinathan, 2012; Gregory \& Clarke, 2003).

Singapore is also influenced by contemporary trends in education. Accountability pressure is constant, given the high social and economic stakes of standardized assessments for students, parents, teachers, and schools (Ng, 2010). The centralized teacher education system, while highly regarded, is also undergoing changes to incorporate new technological tools and to respond to educational models (Tan, 2018). At the same time, the Ministry of Education (2010) has adopted policies that target twenty-first century skills and promote innovation and adaptiveness. That has meant a move to soften the examination pressure, to provide multiple pathways for student advancement and recognition, and to promote alternative assessment practices at the school and classroom levels.

\section{The role of action research in the system}

Action research has been promulgated in Singapore by the Ministry of Education since 2000, during the introduction of a teacher collaborative platform called Learning Circles (Hairon, 2017), and has continued to be promoted in Singaporean schools at all levels in the past decade (Soh, 2011). Promotion of action research has resulted from education policymakers' recognition of the need for innovations and improvements in the education system so that the Singaporean workforce can meet its future economic needs. Additionally, the Singapore Ministry of Education 
encourages use of action research as part of its school management and evaluation structures, such as the School Excellence Model and the Enhanced Performance Management System.

Singapore strives to be a leader in educational excellence, with attention to lessons learned from other countries and with extensive efforts at its own innovations. In examining the educational innovations in Singapore's system, the Organization for Economic Cooperation and Development (Organisation for Economic Cooperation and Development [OECD] , 2014) found Singapore's top five innovations in organizational policy and practice to be: (1) more use of incentives for secondary teachers; (2) more external evaluation of primary and secondary school classrooms; (3) more parental involvement in school projects, programs, and trips; (4) more peer evaluation of teachers in secondary education; and (5) more enrichment education for secondary science students.

These innovations cannot succeed without research-especially action research. While one cannot estimate in isolation the extent to which action research helps Singapore achieve its educational innovations and its relatively high PISA and TIMSS results, it likely plays a meaningful role due to the importance of standardized assessments and school ranking within the Singaporean system. In a context that prioritizes students' performance, teachers may use action research as a way to incorporate new instructional approaches iteratively while ensuring that student learning outcomes are at least as good as what would be achieved with traditional methods of instruction (Goh \& Goh, 2006). In this way, action research provides a mechanism for supporting classroom innovation while keeping in mind a consistent learning goal.

\section{Papers in this special issue}

Hairon (2017) presents an overview of action research as it has been adopted and implemented in Singapore. This paper updates and expands on Hairon's (2006) paper on action research in this setting, discussing how action research has been officially promoted, but also reviewing some of the challenges that face teachers who enact action research. It discusses some of the presumptions and priorities in action research, compares action research to other approaches common to the system, such as lesson study and professional learning communities, and looks at the skills, expectations, and work culture needs for successful action research.

Fernandez (2017) conducts a quasi-experiment on students' learning of thermal physics, comparing an inquiry-based instruction approach in one classroom with traditional instruction in two other classes. The inquiry-based approach helped improve the students' conceptual understanding and their sense of self-efficacy. The findings demonstrate that inquiry-oriented approaches can be implemented effectively in Singaporean secondary classrooms, with results for both traditional learning outcomes as well as affective ones.

Chua et al. (2017) report findings from a study of feedback order for chemistry and mathematics secondary students. Previous work on feedback has suggested that score reporting tends to detract from students' attention to written comments. But to withhold scores would be roundly criticized in the Singaporean context, where parents and 
students pay great attention to grades and performance. By delaying score reporting until after students have received and responded to written feedback, the authors find that the benefits of descriptive comments can be maintained.

Long and Bae (2018) report on interviews with beginning primary school teachers where they discuss their conceptions of science inquiry and their challenges in implementing inquiry in their classes. This work differs from conventional views of action research because the teacher focuses on novice teachers' views and practices as they grapple with the transition to full-time teaching and the use of inquiry-oriented approaches, while dealing with challenges including assessment expectations and lack of resources and planning time.

Teo et al. (2017) report on a teacher's experience with participatory action research (PAR) where the teacher and students engaged in cogenerative dialogue (cogen) sessions. The goal of the sessions was to help the teacher transition from a teachercentered approach to a more student-centered approach using insights from the cogen and with co-teaching by the researcher. The findings serve as a case study in the process of using cogen to transform one's teaching and show the potential for benefits of cogen in the Singapore context.

\section{Lessons from this special issue}

The papers included in this special issue are all built around teachers' experiences planning, conducting, and reporting on their school-based research projects. The educational level varies from primary school to secondary school. The subject matter also varies widely: physics, chemistry, biology, mathematics, and elementary science. The scope of the research varies from cogenerative dialogue sessions, to classroom units, to interviews with teachers about their experiences across units. This is intentional. An analysis of research presented at a local conference in Singapore revealed that 71 projects were related to action research (Tan et al., 2009). Of these, $86 \%$ used quantitative methodologies and the remaining $14 \%$ used qualitative or mixed methodologies. That more teachers adopted quantitative methods may be explained by the accountability pressures that teachers feel as they must demonstrate the effectiveness of their lessons as stipulated by the Enhanced Performance Management System. The studies in this special issue provide a wide perspective, as they include more qualitative and mixed methods work in addition to quantitative work. The breadth and variability of methodologies allows this set of papers to offer a valuable new perspective of action research in the Singapore context.

The salient emerging theme from these papers is that teachers can serve as knowledgeable partners for research that can contribute directly to the academic debate. The teachers writing these special issue papers are drawing ideas from the academic literature to design and conduct teacher-driven research that touches directly on problems arising in school contexts. Through these partnerships, the papers are then able to draw inferences and communicate directly back to the academic literature. Scholars can read these papers as direct contributions to the body of literature in their respective fields. The pieces can also be seen as highlights of the quality work that teachers can lead with the collaborative support from university partners. 
The key lessons from our special issue are that teachers are not simply consumers of research and that action research need not be confined to informing professional development or iterative lesson improvement. Instead, strategic partnerships among teachers and university-based researchers can provide opportunities to find classroom implications from previous literature and to expand the literature based on research that has close ties to teachers' own experiences. While previous work on action research has often positioned it as a professional development exercise, collaborative work between teachers and researchers can yield findings that can speak back to the academic setting.

We encourage researchers in other settings to build similar connections with teachers that aim to empower them to take the lead in formulating research questions and pursuing promising research alongside faculty members. In this way, we advocate for teachers and their students to be positioned to contribute more equally to the examination of scholarly problems in school settings. We especially hope to see more research like this conducted in the Asia-Pacific region and for the findings of these collaborations to be shared with readers of Asia-Pacific Science Education (APSE). We believe APSE can continue to lead the way in providing a channel for disseminating research that can make a difference in the teaching and learning of science in the region and beyond (for more information, see Martin \& Chu, 2015).

Funding

The authors received no funding for this special issue.

Open access

This article is distributed under the terms of the Creative Commons Attribution 4.0 International License (http:// creativecommons.org/licenses/by/4.0/), which permits unrestricted use, distribution, and reproduction in any medium, provided you give appropriate credit to the original author(s) and the source, provide a link to the Creative Commons license, and indicate if changes were made.

\section{Authors' contribution}

All three authors supported the development of the special issue by working with authors and reviewers to prepare high quality research for the journal. All three authors worked to develop the editorial to describe and introduce the research in the special issue. All authors read and approved the final manuscript.

\section{Author's information}

Gavin Fulmer is an Assistant Professor at University of lowa in lowa City, USA, and was formerly in the Curriculum, Teaching, \& Learning Group at Singapore's National Institute of Education. His research focuses on development, application, and implications of assessment in science education. Hye-Eun Chu is a Lecturer at Macquarie University in Sydney, Australia, and was formerly in the Natural Sciences and Science Education Group at Singapore's National Institute of Education. Her research focuses on monitoring students' conceptual development and formative assessment practices in science classrooms. Sonya Martin is an Associate Professor of Science Education at Seoul National University in Korea. For many years, she has conducted classroom-based research with teachers and students using action research methodologies to improve science teaching and learning.

\section{Competing interest}

The authors declare that they have no competing interests.

\section{Publisher's Note}

Springer Nature remains neutral with regard to jurisdictional claims in published maps and institutional affiliations.

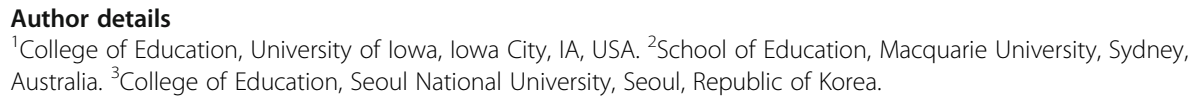


Chua, H. L., Lee, S. H., \& Fulmer, G. W. (2017). Action research on the effect of descriptive and evaluative feedback order on student learning in a specialized mathematics and science secondary school. Asia-Pacific Science Education, 3(4). https://doi.org/10.1186/s41029-017-0015-y.

Fernandez, F. B. (2017). Action research in the physics classroom: The impact of authentic, inquiry based learning or instruction on the learning of thermal physics. Asia-Pacific Science Education, 3(3). https://doi.org/10.1186/s41029-017-0014-z.

Goh, S. H. J. J., \& Goh, T. K. (2006). Using inquiry-based instruction for the teaching of electricity in physics. In Celebrating learning through active research: CLEAR symposium 2006 (pp. 279-283). Singapore: North Zone Schools, Ministry of Education.

Gopinathan, S. (2012). Fourth way in action? The evolution of Singapore's education system. Educational Research for Policy and Practice, 11, 65-70.

Gregory, K., \& Clarke, M. (2003). High-stakes assessment in England and Singapore. Theory Into Practice, 42(1), 66-74.

Hairon, S. (2006). Action research in Singapore education: Constraints and sustainability. Educational Action Research 14(4), 513-523.

Hairon, S. (2017). Action research in Singapore: Where are we now? Asia-Pacific Science Education, 3(5). https://doi.org/ 10.1186/s41029-017-0016-X.

Kennedy, K. J. (2007). Barriers to innovative school practice: A socio-cultural framework for understanding assessment practices in Asia. In Paper presented at redesigning pedagogy: Culture. Understanding and: Practice. Singapore.

Long, S. C. J., \& Bae, Y. (2018). Action research: First-year primary school science teachers' conceptions on and enactment of science inquiry in Singapore. Asia-Pacific Science Education, 4(2). https://doi.org/10.1186/s41029-0170017-9.

Martin, S., \& Chu, H. E. (2015). Asia-Pacific science education (APSE): Expanding opportunities for publishing science education research. Asia-Pacific Science Education, 1(3), 1-18 https://doi.org/10.1186/s41029-015-0006-9.

Ministry of Education. (2010). Nurturing our young for the future: Competencies for the 21st century. Singapore: Author.

$\mathrm{Ng}$, P. T. (2010). The evolution and nature of school accountability in the Singapore education system. Educational Assessment, Evaluation \& Accountability, 22(4), 275-292. https://doi.org/10.1007/s11092-010-9105-z.

Organisation for Economic Cooperation and Development [OECD]. (2014). Measuring innovation in education: Singapore country note. Paris: Author. Retrieved 24 MAR 2018 from http://www.oecd.org/education/ceri/ Measuring-Innovation-in-Education-Singapore.pdf

Soh, K. C. (2011). At the rear mirror and through the wind screen: Teachers becoming teacher-researchers in Singapore schools. New Horizons in Education, 59(1), 12-24.

Tan, A.-L. (2018). Journey of science teacher education in Singapore: Past, present and future. Asia-Pacific Science Education, 4(1). https://doi.org/10.1186/s41029-017-0018-8.

Tan, W. K., Macdonald, D., \& Rossi, T. (2009). Educational action research in Singapore: To prove or improve? Asia Pacific journal of education, 29(3), 357-371.

Tang, N. (2000). Teachers' network: A new approach in the professional development of teachers. ASCD Review, 9(3), $48-55$.

Teo, T. W., bin Badron, M. F. \& Tan, A.-L. (2017). Enabling classroom change by infusing cogen and coteaching in participatory action research. Asia-Pacific Science Education, 3(6). https://doi.org/10.1186/s41029-017-0019-7.

\section{Submit your manuscript to a SpringerOpen ${ }^{\circ}$} journal and benefit from:

- Convenient online submission

- Rigorous peer review

Open access: articles freely available online

High visibility within the field

Retaining the copyright to your article 